\title{
Phosphatidylglycerol homeostasis in glycerol-phosphate auxotrophs of Staphylococcus aureus
}

\author{
Joshua B Parsons", Jiangwei Yao, Pamela Jackson, Matthew Frank and Charles O Rock
}

\begin{abstract}
Background: The balanced synthesis of membrane phospholipids, fatty acids and cell wall constituents is a vital facet of bacterial physiology, but there is little known about the biochemical control points that coordinate these activities in Gram-positive bacteria. In Escherichia coli, the glycerol-phosphate acyltransferase (PIsB) plays a key role in coordinating fatty acid and phospholipid synthesis, but pathogens like Staphylococcus aureus have a different acyltransferase (PIsY), and the headgroup of the major membrane phospholipid, phosphatidylglycerol (PtdGro), is used as a precursor for lipoteichoic acid synthesis.
\end{abstract}

Results: The PIsY acyltransferase in S. aureus was switched off by depriving strain PDJ28 ( $\triangle g p s A)$ of the required glycerol supplement. Removal of glycerol from the growth medium led to the rapid cessation of phospholipid synthesis. However, the continued utilization of the headgroup caused a reduction in PtdGro coupled with the accumulation of CDP-diacylglycerol and phosphatidic acid. PtdGro was further decreased by its stimulated conversion to cardiolipin. Although acyl-acyl carrier protein (ACP) and malonyl-CoA accumulated, fatty acid synthesis continued at a reduced level leading to the intracellular accumulation of unusually long-chain free fatty acids.

Conclusions: The cessation of new phospholipid synthesis led to an imbalance in membrane compositional homeostasis. PtdGro biosynthesis was not coupled to headgroup turnover leading to the accumulation of pathway intermediates. The synthesis of cardiolipin significantly increased revealing a stress response to liberate glycerol-phosphate for PtdGro synthesis. Acyl-ACP accumulation correlated with a decrease in fatty acid synthesis; however, the coupling was not tight leading to the accumulation of intracellular fatty acids.

Keywords: Acyl carrier protein, PIsY, Acyl-phosphate, Phosphatidylglycerol, S. aureus

\section{Background}

The maintenance of membrane lipid homeostasis is a vital process in bacterial metabolism [1]. The synthesis of membrane proteins and lipids is coordinated in Escherichia coli to ensure that the biophysical properties of the membrane remain constant regardless of the growth rate or environmental stress. Overexpression of the pathway enzymes does not increase the amount of lipid in the cell illustrating the stringent biochemical regulation of the pathway that precisely matches the rate of fatty acid synthesis to the demand for new membrane. The biochemical regulation of type II fatty acid

\footnotetext{
* Correspondence: josh.parsons@stjude.org

Department of Infectious Diseases, St. Jude Children's Research Hospital, 262 Danny Thomas Place, Memphis TN 38105, USA
}

synthesis (FASII) in bacteria is most completely studied in Escherichia coli [2-4]. The scheme that has emerged places the first committed step in membrane phospholipid synthesis, $s n$-glycerol-3-phosphate (glycerol- $\mathrm{PO}_{4}$ ) acyltransferase (PlsB), as a key regulatory point. How $\mathrm{PlsB}$ senses the requirement for new phospholipid is not completely understood, but one biochemical regulator is ppGpp [5], a global regulator of gene expression [6]. The consequences of regulation at the PlsB step are relayed to FASII by long-chain acyl-acyl carrier protein (ACP), a crucial allosteric regulator of two steps in initiation. The importance of acyl-ACP was first recognized by the expression of acyl-ACP thioesterases in E. coli, which leads to run-away FASII activity and the secretion of copious amounts of free fatty acids [7-9]. Long-chain acyl-ACPs act as potent feedback inhibitors of FASII by 
blocking the initiation of new acyl chains at the FabH step $[10,11]$ and slowing the elongation of acyl chains by inhibiting acetyl-CoA carboxylase [12]. It is not clear whether this regulatory model for membrane lipid homeostasis in E. coli can be extended to Gram-positive bacteria. Notably, these organisms do not have a PlsB acyltransferase, but rather use a novel activated acyl donor, acyl-phosphate (acyl- $\mathrm{PO}_{4}$ ), produced by PlsX from the acyl-ACP end-products of FASII, and have a unique glycerol- $\mathrm{PO}_{4}$ acyltransferase, PlsY, which only uses acyl- $\mathrm{PO}_{4}$ [13]. Precise control over fatty acid synthesis appears even more important for Gram-positive pathogens like $S$. aureus, because unlike E. coli, they lack a fatty acid catabolic pathway [14]. Expression of the genes responsible for phosphatidic acid biosynthesis in Bacillus subtilis and S. aureus is controlled by FapR [15], which releases from its DNA binding sites within the regulons multiple promoters when bound to malonylCoA $[16,17]$. Although the transcriptional regulation of lipid synthesis is understood in considerable detail, much less is known about the biochemical regulation of FASII or the coupling of fatty acid and phospholipid synthesis.

Glycerol- $-\mathrm{PO}_{4}$ is the substrate for PlsY and a required precursor for membrane phospholipid synthesis, and is produced from dihydroxyacetone phosphate by glycerol$\mathrm{PO}_{4}$ synthase (GpsA) [18]. Forty years ago Mindich [19] isolated a $S$. aureus glycerol auxotroph and demonstrated that phospholipid synthesis from $\left[{ }^{14} \mathrm{C}\right]$ acetate ceased abruptly following removal of the glycerol growth supplement, although free fatty acids continued to accumulate. Subsequent work revealed that the free fatty acids consisted primarily of 21-carbon branched-chain species that are longer than the normal 15-17 carbon fatty acids in normally growing cells [20]. Total protein synthesis continued following the removal of glycerol resulting in denser cells [20]. Protein synthesis also continued when glycerol was withheld from Bacillus subtilis glycerol auxotrophs illustrating that protein and lipid synthesis are not tightly coupled in Gram-positive bacteria [21,22]. A different approach was used by Paoletti et al. [23] who inactivated $p l s Y$ in B. subtilis with an intact $p l s Y$ gene under control of a regulated promoter. In this model, the inactivation of PlsY activity is not immediate or complete, but rather the strain must be grown for hours to deplete pre-existing PlsY protein. Nonetheless, fatty acid accumulation was detected in PlsY-depleted cells [23].

These earlier experiments did not investigate the effect of glycerol deprivation on either the membrane lipid composition or the level or composition of the lipid precursor pools. Because knowledge of these metabolic intermediates will provide insight into the role of PlsY in pathway regulation, we constructed a gpsA knockout in $S$. aureus to more precisely investigate the regulation of
FASII and phospholipid metabolism in the absence of PlsY activity. The cessation of phospholipid synthesis does not blunt the continued metabolism of the principle membrane phospholipid, phosphatidylglycerol (PtdGro), resulting in a marked disruption of membrane phospholipid homeostasis. Long-chain acyl-acyl carrier protein (ACP) and malonyl-CoA accumulate following the block at PlsY, but fatty acid synthesis continues at a reduced rate reflected by the accumulation of intracellular fatty acids.

\section{Methods}

\section{Bacterial strains and media}

S. aureus strain RN4220 was obtained from Richard Novick [24]. Strain PDJ28 ( $\triangle g p s A)$ was constructed as described previously [25]. A group II intron was inserted at bp 42 of the gpsA gene using the primer design software and plasmid system provided by Sigma-Aldrich (Targetron system) [26]. The presence of the insertions was verified by multiplex PCR using opposing primers located in the gpsA gene outside the intron insertion site and one primer inside the intron. The wild-type allele yields a product of $528 \mathrm{bp}$ and the disrupting gene gives a product of $394 \mathrm{bp}$. RN minimal medium was used for broth cultures and consisted of M9 salts, $1 \mathrm{mM} \mathrm{MgSO}_{4}, 10 \mathrm{mM} \mathrm{CaCl}_{2}, 15 \mu \mathrm{M}$ vitamin $B_{1}, 32 \mu \mathrm{M}$ vitamin $B_{3}, 0.1 \%$ casein hydrolysate, $0.4 \%$ glucose, $0.1 \mathrm{mg} / \mathrm{l}$ biotin, $2 \mathrm{mg} / \mathrm{l}$ pantothenic acid, $10 \mu \mathrm{M}$ $\mathrm{FeCl}_{2}, 6 \mathrm{mg} / \mathrm{l}$ citrate, $10 \mathrm{mg} / \mathrm{l} \mathrm{MnCl}_{2}, 4 \mu \mathrm{g} / \mathrm{l}$ L-tryptophan, and $0.1 \mathrm{mg} / \mathrm{l}$ lipoic acid.

\section{Metabolic labeling}

Phospholipids and fatty acids were labeled by the addition of $50 \mu \mathrm{Ci}\left[1-{ }^{14} \mathrm{C}\right]$ acetate $(50 \mathrm{Ci} / \mathrm{mol})$ per $10 \mathrm{ml}$ culture. For labeling of lipids before glycerol starvation, $\mathrm{RN}$ media supplemented with $0.1 \%$ glycerol and $50 \mu \mathrm{Ci}\left[1-{ }^{14} \mathrm{C}\right]$ acetate $(1 \mathrm{Ci} / \mathrm{mol})$ per $10 \mathrm{ml}$ culture was inoculated with strain PDJ28 to $\mathrm{OD}_{600}=0.05$ and grown to $\mathrm{OD}_{600}=0.6$. The cells were pelleted and washed with $50 \mathrm{ml} \mathrm{RN}$ media and used to inoculate cultures in RN media with and without $0.1 \%$ glycerol supplement for indicated time. For labeling of lipids after glycerol starvation, cells were washed as previously described, grown for 30 minutes before addition of $50 \mu \mathrm{Ci}\left[1-{ }^{14} \mathrm{C}\right]$ acetate $(50 \mathrm{Ci} / \mathrm{mol})$ per $10 \mathrm{ml}$ culture for indicated time. $10 \mathrm{ml}$ samples were centrifuged, washed with $10 \mathrm{ml} \mathrm{RN}$ media and $10 \mathrm{ml} \mathrm{H}_{2} \mathrm{O}$. Pellets were resuspended in $100 \mu \mathrm{l} \mathrm{H}_{2} \mathrm{O}$ and lipids extracted through the addition of $360 \mu \mathrm{l}$ of chloroform:methanol: $\mathrm{HCl}(1 / 2 / 0.02)$ and incubated at room temperature for 20 minutes. $120 \mu \mathrm{l}$ chloroform and $120 \mu \mathrm{l} 2 \mathrm{M} \mathrm{KCl}$ were added to separate phases and after centrifugation, the organic phase was removed and radioactivity quantified by scintillation counting.

\section{Thin-layer chromatography}

Radiolabelled lipids were analyzed by 1-dimensional and 2dimensional thin-layer chromatography. The 1-dimensional 
system used to separate phospholipids from diacylglycerol and fatty acid was Silica Gel G layers developed with chloroform:methanol:acetic acid (98/2/1) and visualized using Bioscan imaging detector. The 2-dimensional system also employed Silica Gel G layers and was developed first with chloroform:methanol:water (65/25/4) and secondly tetrahydrofuran/dimethoxyethane/methanol/4 $\mathrm{M}$ ammonium hydroxide (10/6/4/1). The resulting thin-layer plate exposed to a PhosphoImager screen and visualized using a Typhoon 9200.

\section{Lipid mass spectrometry}

Mass spectrometry of phospholipids was performed using a Finnigan TSQ Quantum (Thermo Electron, San Jose, CA) triple quadrupole mass spectrometer. Samples were prepared in 50:50 (v/v) chloroform:methanol. The instrument was operated in the negative ion mode. Ion source parameters were as follows: spray voltage of 3,000 V, capillary temperature of $270^{\circ} \mathrm{C}$, capillary offset of $35 \mathrm{~V}$, and the tube lens offset was set by infusion of polytyrosine tuning and calibration solution (Thermo Electron, San Jose, CA) in the electrospray mode. Acquisition parameters were as follows: full scan, scan range $600-100 \mathrm{~m} / z$, scan time $0.5 \mathrm{~s}$, peak width Q1 0.7 FWHM. Instrument control and data acquisition was performed with the Finnigan ${ }^{\text {tax }}$ Xcalibur $^{\text {mit }}$ software (Thermo Electron, San Jose, CA).

\section{Mass spectrometry malonyl-CoA measurement}

Cultures of strain PDJ28 were grown in RN medium supplemented with $0.1 \%$ glycerol to $\mathrm{OD}_{600}=0.6$. Cells were pelleted and washed with $50 \mathrm{ml}$ RN medium to remove glycerol and used to inoculate $\mathrm{RN}$ medium with and without $0.1 \%$ glycerol. Cultures were grown for 120 minutes and harvested at room temperature. Cells were extracted using the Bligh and Dyer method [27], and 50 pmol of $\left[{ }^{13} \mathrm{C}_{3}\right]$ malonyl-CoA (Stable Isotope Products; Isotec) was added. The aqueous phase was applied to a 100-mg 2-(2-pyridyl)ethyl functionalized silica gel column (Supelco) equilibrated with $2 \%$ acetic acid in methanol/ water (1:1) [28]. The column was washed two times with $1 \mathrm{ml}$ of equilibration buffer and $1 \mathrm{ml}$ water. CoAs were eluted with $1 \mathrm{ml}$ of $50 \%$ acetonitrile containing $15 \mathrm{mM}$ ammonium hydroxide. Mass spectrometry of acyl-CoA was performed using a Finnigan TSQ Quantum (Thermo Electron) triple-quadrupole mass spectrometer [29]. The instrument was operated in positive mode using single ion monitoring (SIM) neutral loss scanning corresponding to the loss of the phosphoadenosine diphosphate from CoA species. The ion source parameters were as follows: spray voltage, $4,000 \mathrm{~V}$; capillary temperature, $250^{\circ} \mathrm{C}$; capillary offset, $-35 \mathrm{~V}$; sheath gas pressure, 10 ; auxiliary gas pressure, 5; and tube lens offset was set by infusion of the polytyrosine tuning and calibration in electrospray mode. Acquisition parameters were as follows: scan time, $0.5 \mathrm{~s}$; collision energy, $30 \mathrm{~V}$; peak width Q1 and Q3, 0.7 FWHM; Q2 CID gas, 0.5 mTorr; source CID, $10 \mathrm{~V}$; neutral loss, $507.0 \mathrm{~m} / \mathrm{z}$; SIM mass of $855 \mathrm{~m} / \mathrm{z}$ with a scan width of $10 \mathrm{~m} / z$ to capture the signals from both light and heavy malonyl-CoA, and SIM mass of $810 \mathrm{~m} / z$ with a scan width of $6 \mathrm{~m} / z$ to capture the signal of acetyl-CoA.

\section{ACP immunoblotting}

Cultures of strain PDJ28 ( $\triangle g p s A)$ and parent S. aureus strain RN4220 cells were grown to $\mathrm{OD}_{600}=0.5$ in $\mathrm{RN}$ minimum media with $1 \%$ glycerol supplementation at $37^{\circ} \mathrm{C}$ with rigorous shaking (225 rpm), and then split into $50 \mathrm{ml}$ aliquots. Cells were washed twice with RN media. For PDJ28 without glycerol supplement and strain RN4220, cells were suspended in $50 \mathrm{ml}$ of RN media. Strain PDJ28 was grown in RN media with $1 \%$ glycerol supplementation. Cells were grown for the indicated amount of time, pelleted, and resuspended in $125 \mu \mathrm{l}$ of $25 \%$ sucrose and $50 \mathrm{mM}$ Tris $\mathrm{pH} 7.0$ on ice. Lysostaphin $(25 \mu \mathrm{l}$ of a $5 \mathrm{mg} / \mathrm{ml})$ was added to the mixture, and incubated on ice for 15 minutes. Finally, the cells were lysed by adding $200 \mu \mathrm{l}$ of $10 \%$ Triton X-100, $62.5 \mathrm{mM}$ EDTA, and $50 \mathrm{mM}$ Tris- $\mathrm{HCl} \mathrm{pH} 7.5$. The lysed cells were centrifuged at 40,000 g for 30 minutes. The supernatant, in native loading buffer, was loaded onto a $2.5 \mathrm{M}$ urea, $15 \%$ acrylamide gel. The amount of supernatant loaded in each sample is adjusted to $\mathrm{OD}_{600}$ such that total protein is similar for each lane.

\section{Gas chromatography}

Cultures of strain PDJ28 cells were grown in RN media with $1 \%$ glycerol supplement at $37^{\circ} \mathrm{C}$ with rigorous shaking $(225 \mathrm{rpm})$. Cells were grown to $\mathrm{OD}_{600}$ of 0.5 , aliquoted to $50 \mathrm{ml}$ cultures, and washed twice with RN media. Then, one cell aliquot was grown in RN minimum media and another aliquot was grown in $\mathrm{RN}$ minimum media supplemented with $1 \%$ glycerol for an additional 2 hours. Cells were washed with phosphate-buffered slaine three times and harvested for lipids using the method of Bligh and Dyer [27]. The free fatty acids were separated from the other lipid species by thin-layer chromatography. Briefly, the lipid extract was loaded onto Silica Gel G plates (Analtech) and chromatographed in chloroform: methanol:acetic acid (98/2/1) solvent mixture. The silica gel at $R_{f}$ of 0.7 or higher was scraped off the plate to collect the free fatty acid fractions. The scraped silica was added to $1 \mathrm{ml}$ water, and extracted 3 times with $1 \mathrm{ml}$ hexane. The hexane fractions were collected and evaporated to obtain the free fatty acid samples. Fatty acid methyl esters were generated from the collected fatty acids by bringing up the fatty acid samples in $5 \mathrm{ml}$ of $2 \%$ anhydrous $\mathrm{HCl}$ in anhydrous methanol and incubating overnight. The reaction was evaporated under nitrogen and brought up in $1 \mathrm{ml}$ of distilled water. The 
water phase was extracted 3 times with hexanes. The hexane fractions were pooled and evaporated over nitrogen. The fatty acid methyl esters were analyzed by a HewlettPackard model 5890 gas chromatograph equipped with a flame ionization detector, and separated on $30 \mathrm{~m} \times$ $0.536 \mathrm{~mm} \times 0.50 \mu \mathrm{m} \mathrm{DB}-225$ capillary column. The injector was set at $250^{\circ} \mathrm{C}$, and the detector was at $300^{\circ} \mathrm{C}$. The temperature program was as followed: initial temp $70^{\circ} \mathrm{C}$ for $2 \mathrm{~min}$, rate of $20^{\circ} \mathrm{C} / \mathrm{min}$ for $5 \mathrm{~min}$ (final $170^{\circ} \mathrm{C}$ ), rate of $2^{\circ} \mathrm{C} / \mathrm{min}$ for $10 \mathrm{~min}$ (final $190^{\circ} \mathrm{C}$ ), hold at $190^{\circ} \mathrm{C}$ for $5 \mathrm{~min}$, rate of $2^{\circ} \mathrm{C} / \mathrm{min}$ for $15 \mathrm{~min}$ (final $220^{\circ} \mathrm{C}$ ), hold at $220^{\circ} \mathrm{C}$ for $5 \mathrm{~min}$. The identity of fatty acid methyl esters were determined by comparing their retention times with identified fatty acid methyl ester standards (Sigma-Aldrich). The compositions were expressed as weight percentages.

\section{Results}

Growth characteristics of S. aureus strain PDJ28 ( $\Delta g p s A)$ The $S$. aureus gpsA gene (SA1306) was disrupted by the insertion of a Group II intron (see Methods). The insertion was confirmed by PCR genotyping showing the presence of the inactivating DNA insertion in the gpsA gene (Figure 1, inset). Strain PDJ28 was a glycerol or glycerol- $\mathrm{PO}_{4}$ auxotroph on agar plates (not shown). The growth of strain PDJ28 in RN media broth was followed

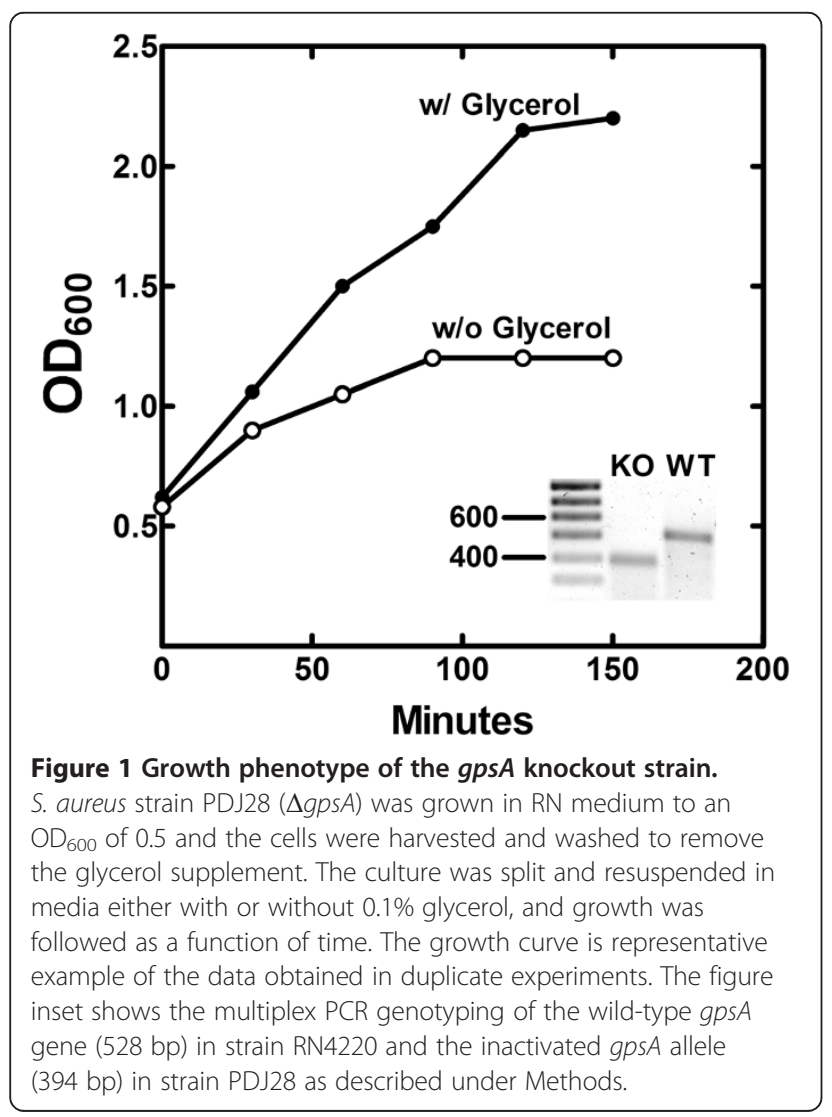

after the removal of the glycerol supplement (Figure 1). The rate of cell growth immediately slowed, and then ceased after $90 \mathrm{~min}$. These growth characteristics were similar to the growth phenotypes of the gps $A$ knockouts previously isolated in E. coli [30], B. subtilis [22] and S. aureus [20].

\section{Alterations in membrane phospholipid homeostasis following glycerol removal}

The removal of the glycerol supplement from strain PDJ28 ( $\triangle g p s A)$ had a significant impact on the membrane

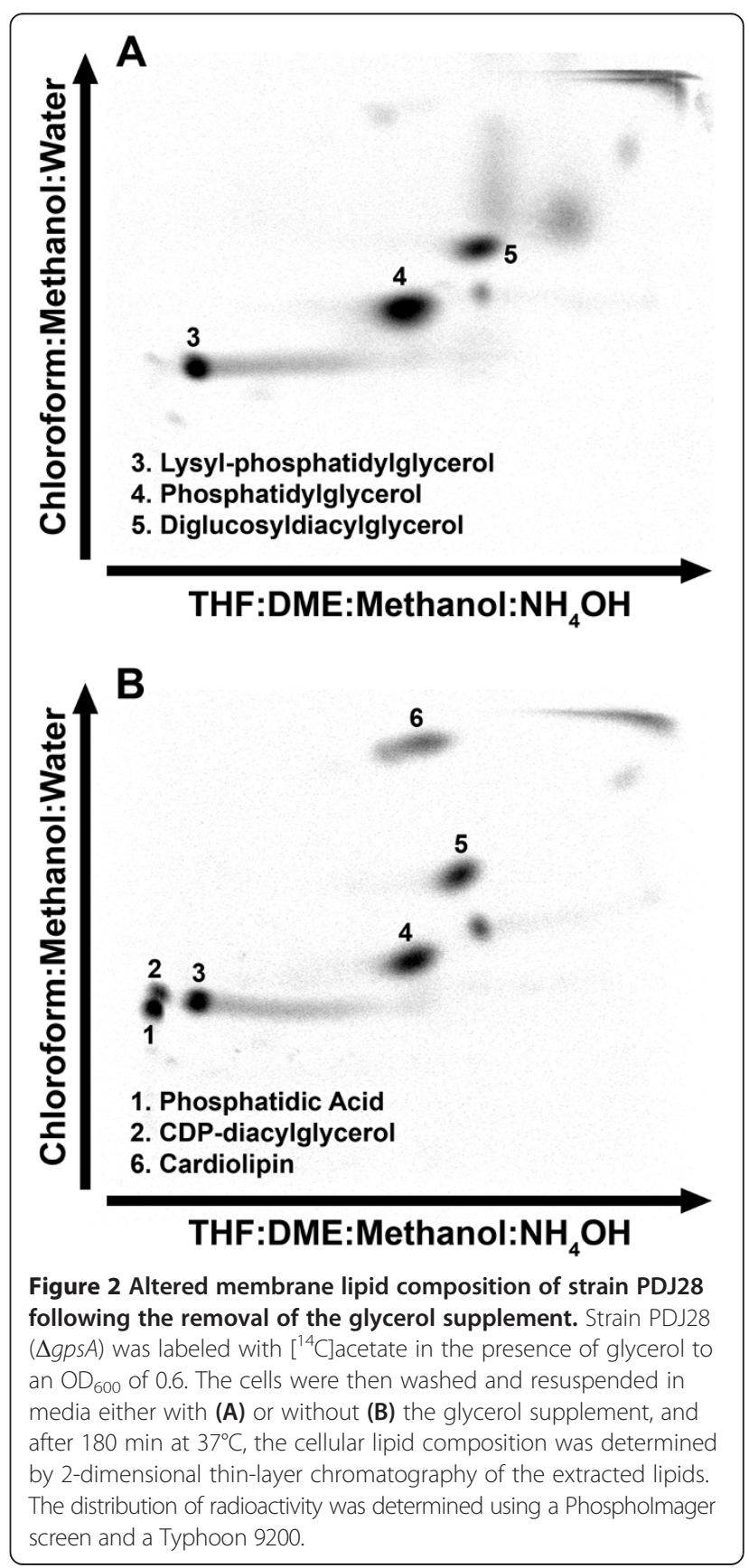


phospholipid composition. The metabolism of existing membrane phospholipids was determined by first labeling the cells with $\left[{ }^{14} \mathrm{C}\right]$ acetate in the presence of glycerol. The $\left[{ }^{14} \mathrm{C}\right]$ acetate and glycerol were then removed from the culture and the distribution of lipid classes examined after $30 \mathrm{~min}$ of glycerol deprivation by 2-dimensional thin-layer chromatography (Figure 2). A clear finding from these compositional analyses was that the metabolism of phosphatidylglycerol (PtdGro) continued in the absence of new synthesis (Table 1). Two polar phospholipids were detected in glycerol-depleted cells that were not detected in the glycerol-supplemented cells. These two phospholipids corresponded to the migration positions of phosphatidic acid $(\mathrm{PtdOH})$ and CDP-diacylglycerol (CDP-DAG) (Figure 2B). These identifications were confirmed by the detection of increased amounts of PtdOH and CDP-DAG by mass spectrometry profiling of the phospholipid classes (Figure 3). These phospholipids would arise from the DAG formed from the transfer of the PdtGro to lipoteichoic acids (LTA). However, due to the lack of glycerol$\mathrm{PO}_{4}$, PtdGro cannot be resynthesized from DAG due to the requirement of PtdGro synthase for glycerol- $\mathrm{PO}_{4}$ leading to the accumulation of the PtdOH and CDPDAG intermediates. The DAG may also be converted to diglucosyl-diacylglycerol ( $\mathrm{Gl}_{2} \mathrm{DAG}$ ); however, $\mathrm{Gl}_{2} \mathrm{DAG}$ levels did not increase. PtdGro was also the precursor to Lys-PtdGro, and the level of Lys-PtdGro did not increase following glycerol removal indicating that the conversion of PtdGro to Lys-PtdGro was coupled to new PtdGro synthesis. A striking change was the increase in cardiolipin content from the low levels characteristic of logarithmically growing cells to $12.5 \%$ of the total phospholipid. These compositional data illustrated that after depletion of the glycerol- $\mathrm{PO}_{4}$ pool, PtdGro metabolism to LTA and cardiolipin continued leading to the depletion of PtdGro, and the accumulation of cardiolipin and biosynthetic intermediates due to the block at the PtdGro synthase step resulting from the absence of glycerol- $\mathrm{PO}_{4}$.

Table 1 Membrane phospholipid metabolism following glycerol deprivation

\begin{tabular}{cccc}
\hline Spot number & Membrane lipid & \multicolumn{2}{c}{ \% total ${ }^{\mathbf{1 4}}$ C-label } \\
\cline { 3 - 4 } & & W/ Glycerol & W/o Glycerol \\
\hline 1 & Phosphatidic acid & $<1$ & 15.1 \\
2 & CDP-diacylglycerol & $<1$ & 6.2 \\
3 & Lysyl-phosphatidylglycerol & 23.2 & 18.4 \\
4 & Phosphatidylglycerol & 55.0 & 28.4 \\
5 & Diglucosyldiacylglycerol & 21.9 & 19.3 \\
6 & Cardiolipin & $<1$ & 12.5 \\
\hline
\end{tabular}
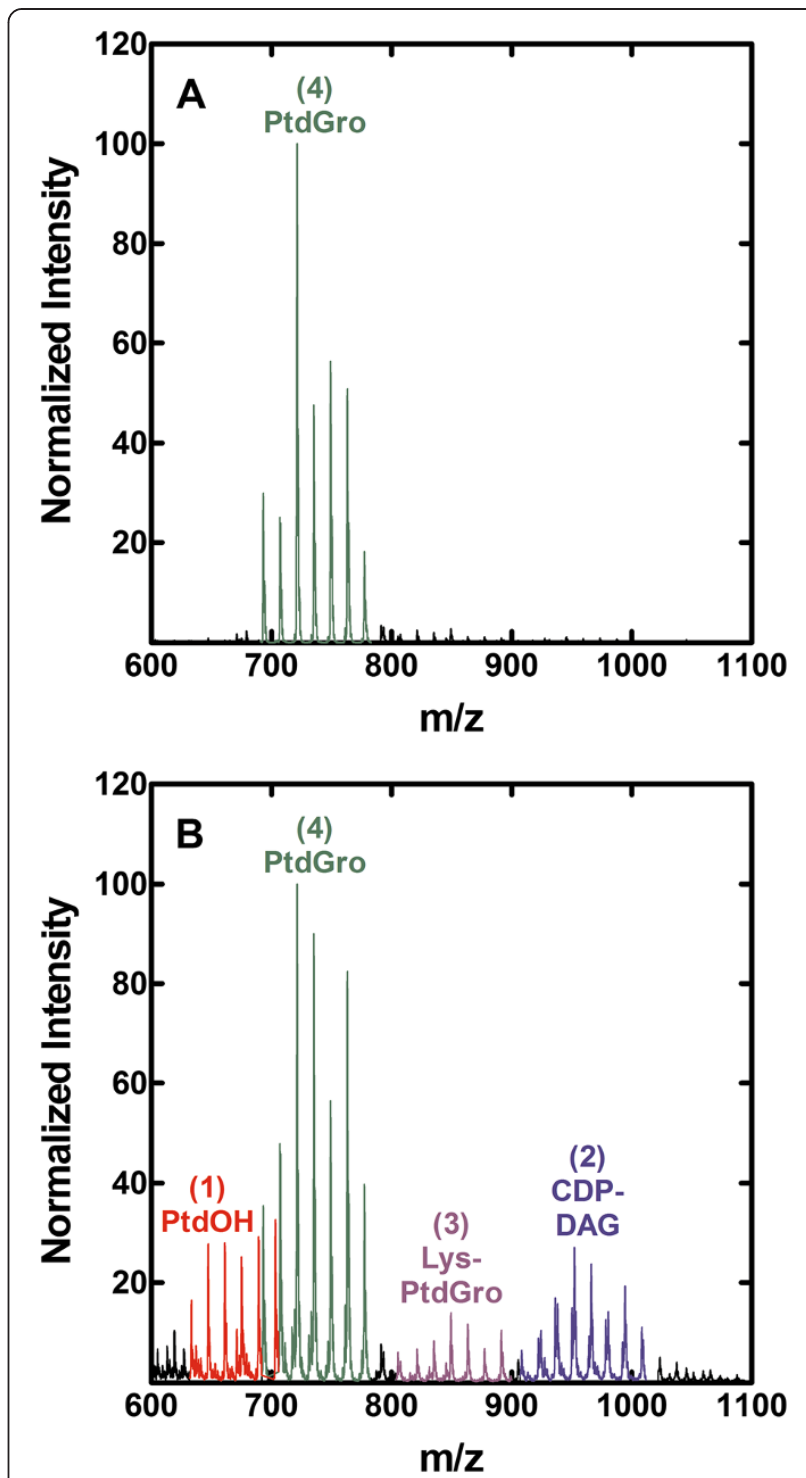

Figure 3 Mass spectrometry identification of $\mathrm{PtdOH}$ and CDP-DAG accumulation following the removal of the glycerol supplement. The identity of the two new polar phospholipid species that appeared in glycerol-starved cells was confirmed by mass spectrometry of the phospholipid fraction in the presence (A) or absence (B) of the glycerol supplement. Samples were prepared and analyzed by mass spectrometry as described in Methods.

\section{Coupling of fatty acid and phospholipid synthesis}

The fate of newly synthesized fatty acids produced following withdrawal of the glycerol supplement were determined by labeling with $\left[{ }^{14} \mathrm{C}\right]$ acetate. The first observation was that the rate of acetate incorporation was significantly reduced, but not eliminated, in glycerol-deprived cells (Figure 4A). There was some residual synthesis of PtdGro, but the most pronounced effect was the accumulation of non-esterified fatty acids in the neutral lipid fraction (Figure 4B \& 4C). Thus, the fatty acids synthesized in glycerol deprived cells were not incorporated into 

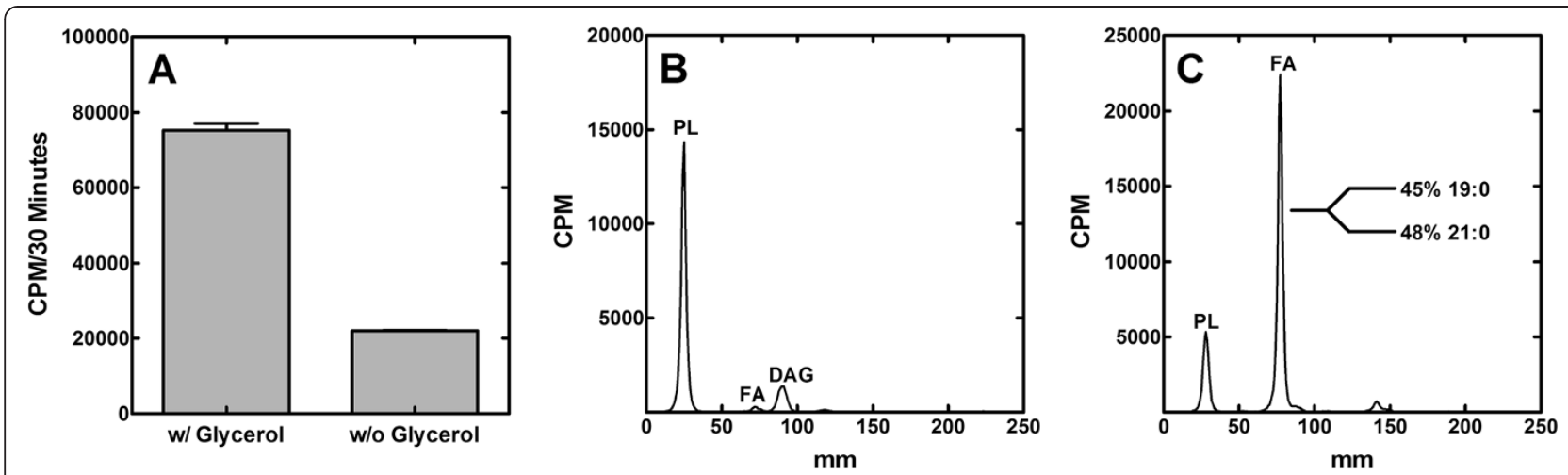

Figure 4 Synthesis of lipid classes from $\left[{ }^{14} \mathrm{C}\right]$ acetate after blocking phospholipid synthesis at the PIsY step. (A) Strain PDJ28 ( $\left.\triangle g p s A\right)$ was grown to an $\mathrm{OD}_{600}$ of 0.5 , the culture was harvested, washed and split into media either with or without the glycerol supplement. The cells were then labeled with $\left[{ }^{14} \mathrm{C}\right]$ acetate for $30 \mathrm{~min}$, the lipids were extracted and the total amount of label incorporated into cellular lipids was determined. The extracted lipids were analyzed by thin-layer chromatography on Silica Gel G layers developed with chloroform:methanol:acetic acid $(98 / 2 / 1, v / v / v)$. The distribution of radioactivity was determined using a Bioscan Imaging detector for the cultures containing the glycerol supplement (B) and the glycerol-deprived cultures (C). The composition of the free fatty acids that accumulated in the glycerol starved cultures was determined by preparative thin-layer chromatography to isolate the fatty acids, followed by the preparation of methyl esters and quantitative analysis by gas-liquid chromatography as described in Methods. The weight percent of the two major fatty acids detected is shown in the figure. All other fatty acids were present at less than $1 \%$ of the total.

phospholipid, but rather accumulated as fatty acids. These fatty acids were identified by gas chromatography following their isolation by preparative thin-layer chromatography from glycerol-depleted cells. The free fatty acid pool consisted of longer chain 19:0 (45\%) and 21:0 (48\%) fatty acids (Figure 4C, inset), which were not normally abundant in $S$. aureus phospholipids. These data showed that fatty acid synthesis continued at a diminished rate in glycerol-deprived cells resulting in the accumulation of abnormally long chain length $(19: 0+21: 0)$ fatty acids as opposed to the 15:0 + 17:0 fatty acids found in the phospholipids of normally growing cells [14]. The longerchain fatty acids arose from the continued action of the FabF elongation enzyme in the absence of the utilization of the acyl-ACP by the PlsX/PlsY pathway.

Next, the time course for the continued synthesis of lipids following glycerol withdrawal was determined (Figure 5). New phospholipid synthesis was noted at the first time point following glycerol deprivation and was attributed to the utilization of intracellular glycerol- $\mathrm{PO}_{4}$ that remained in the cells following the washing procedure. After this initial phase, phospholipid synthesis ceased. In contrast, total lipid synthesis continued, which was entirely due to the accumulation of intracellular free fatty acids. The media was extracted and analyzed, and no extracellular labeled fatty acids were detected. The accumulation of fatty acid was not a linear function of time, but rather became progressively slower. These data indicated that fatty acid and phospholipid synthesis were coupled at the PlsY step, however, the continued synthesis of free fatty acids showed that there was a biochemical pathway to bypass the regulatory steps and accumulate an intermediate that is usually not detected. The fatty acids could come from the hydrolysis of acyl-ACP, but this seems unlikely in light of the observation that fatty acids did not accumulate in a strain depleted of PlsX [23] where acyl-ACP, but not acyl- $\mathrm{PO}_{4}$, would be formed. Thus, it was likely that longchain fatty acids accumulated due to the hydrolysis of the unstable acyl- $\mathrm{PO}_{4}$ formed from acyl-ACP by PlsX when the PlsY step was blocked by glycerol removal.

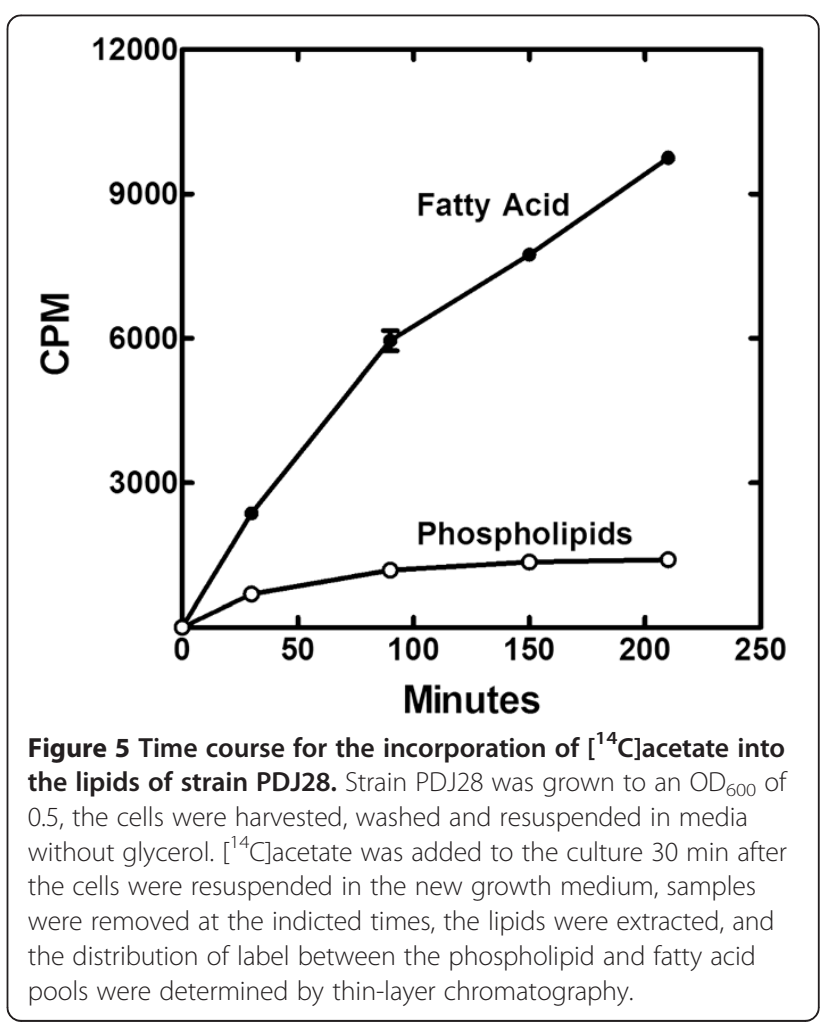




\section{Intracellular intermediate pools following glycerol deprivation}

The decrease in the overall rate of fatty acid synthesis suggested a feedback regulation mechanism that may be similar to that in E. coli where acyl-ACPs are key negative regulators of FASII [4]. We examined the intracellular concentrations of acyl-ACP in strain PDJ28 ( $\Delta g p s A)$ as a function of time following glycerol withdrawal. Interestingly, we consistently observed that there was more acyl-ACP in strain PDJ28 supplemented with glycerol compared to its wild-type counterpart suggesting that PlsY activity was somewhat compromised by GpsA inactivation even in the presence of the media supplement (Figure 6A). Within $30 \mathrm{~min}$ of glycerol removal, the acyl-ACP pool reached $50 \%$ of the total ACP and remained constant for the remainder of the time course. The gel electrophoresis system separates acyl-ACP based
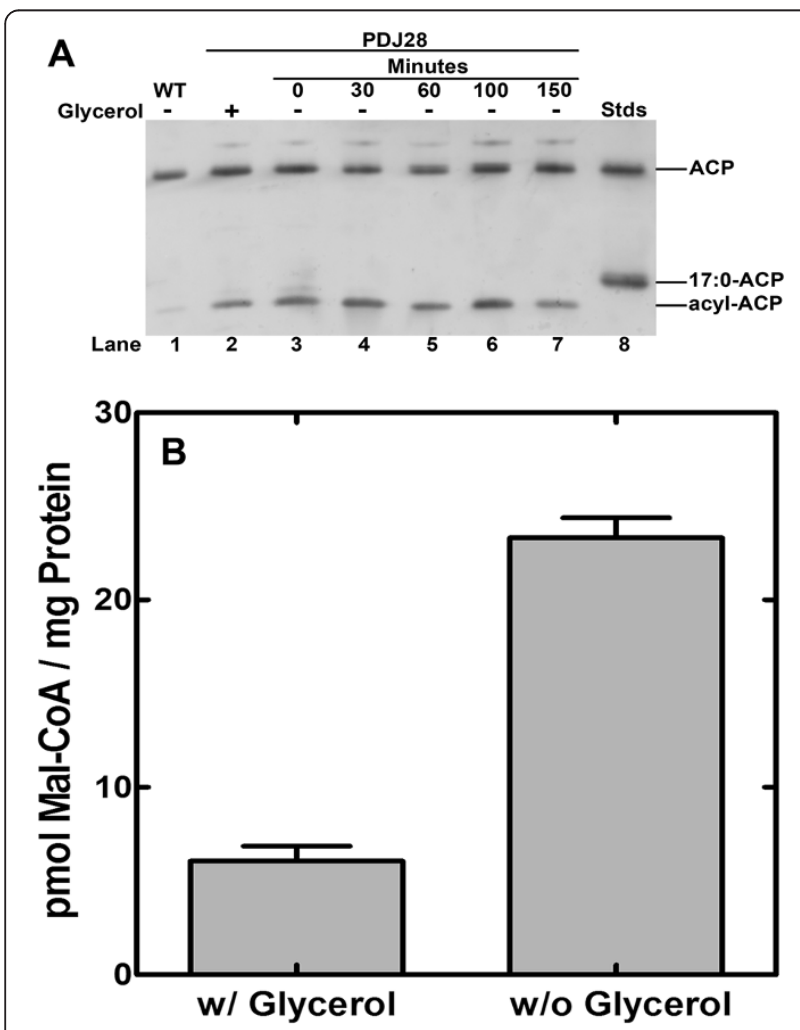

Figure 6 Alteration in intracellular acyl-ACP and malonyl-CoA following the inactivation of PlsY. (A) Cultures of strain PDJ28 $(\triangle g p s A)$ were grown to an $\mathrm{OD}_{600}$ of 0.5 , samples were collected, and then the cells were washed to remove the glycerol supplement and the composition of the ACP pool determined by gel electrophoresis of the cell extracts followed by immunoblotting with anti-ACP antibody as described in Methods. (B) Cultures of strain PDJ28 were grown to an $\mathrm{OD}_{600}$ of 0.5 , the culture was harvested, washed to removed glycerol and resuspended in media either with or without glycerol supplement. After 30 min, triplicate cell cultures were harvested, extracted and malonyl-CoA quantified by mass spectrometry as described in Methods. the nature of the acyl chain, and the fact that the acylACP in the glycerol-starved cultures migrated faster than the 17:0-ACP standard indicated that these acyl-ACP chains were longer than 17 carbons. This conclusion was consistent with the finding that 19:0 and 21:0 fatty acids accumulated in the glycerol-deprived cells (Figure 4C), and these fatty acids would be derived from the acyl-ACP end-products of de novo fatty acid synthesis. These data showed that acyl-ACP did accumulate in the absence of PlsY function, but that not all the ACP was converted to acyl-ACP. Rather a steady state level of acyl-ACP was attained that remained constant for hours. Also, we did not observe any acyl-ACP pathway intermediates, only the pathway end-products. This is in contrast to the effect of an enoyl-ACP reductase inhibitor, which results in almost all of the free ACP being converted to short-chain acyl-ACP [14]. These data indicated the presence of a regulatory mechanism that sensed the long-chain acyl-ACP and inhibited initiation of new acyl chains.

The lack of acyl-ACP intermediate detected in the glycerol-deprived cells suggested that there was sufficient malonyl-CoA present to complete an acyl chain once it was initiated. This question was explored by measuring the intracellular levels of malonyl-CoA in the presence and absence of glycerol by mass spectrometry (Figure 6B). These data showed that malonyl-CoA levels increased following glycerol withdrawal. This observation was consistent with the inhibition of fatty acid synthesis, but at the same time illustrated that there was sufficient malonyl-CoA present to complete the synthesis of any initiated chain in the glycerol-deprived cells. However, the levels of malonyl-CoA remained a minor component of the CoA pool. Acetyl-CoA, the substrate for acetyl-CoA carboxylase, was the most abundant CoA thioester in S. aureus, as it is in E. coli [31]. MalonylCoA was $0.8 \%$ of the acetyl-CoA pool in cells grown in glycerol and only rose to $3.7 \%$ of the acetyl-CoA in the cells deprived of glycerol. These data showed that acetyl-CoA carboxylase activity was also regulated in the absence of phospholipid synthesis because the cells retained a high concentration of acetyl-CoA substrate that was not consumed in the glycerol-deprived cells. The higher levels of malonyl-CoA may also have increased expression of genes controlled by FapR [16,17], although the pathway would remain blocked do the absence of glycerol- $\mathrm{PO}_{4}$.

\section{Discussion}

This study reveals that the synthesis of new membrane PtdGro in $S$. aureus is not tightly coupled to its utilization by other pathways leading to a significant alteration in membrane homeostasis when phospholipid synthesis halts. Removal of the glycerol supplement from strain PDJ28 ( $\triangle g p s A)$ results in the cessation of 
phospholipid synthesis, but the metabolism of PtdGro continues. One major pathway for the metabolism of PtdGro in S. aureus is the transfer of the $s n$-1-glycerol$\mathrm{PO}_{4}$ headgroup of PtdGro to the growing LTA polymer by LtaS [32]. The DAG formed from PtdGro utilization in this pathway has two metabolic fates: 1) DAG is converted to PtdOH by $\mathrm{DkgB}$ [33] and recycled back toward PtdGro via CDP-DAG, or 2) DAG is converted to GlcDAG and $\mathrm{Glc}_{2} \mathrm{DAG}$ by YpfP [34], which serves as the scaffold for glycerol- $\mathrm{PO}_{4}$ polymerization in LTA synthesis. In the absence of a glycerol- $\mathrm{PO}_{4}$ supplement, the PtdGro in the $\Delta g p s A$ cells cannot be remade due to the requirement of PtdGro synthase for glycerol- $\mathrm{PO}_{4}$ resulting in the accumulation of $\mathrm{PtdOH}$ and CDP-DAG intermediates. Interestingly, the levels of neither $\mathrm{Glc}_{2} \mathrm{DAG}$ nor Lys-PtdGro, via MprF [35], increased in the glyceroldepleted cells suggesting that the synthesis of these two membrane lipids is linked to the synthesis of new PtdGro. A striking result was the upregulation of cardiolipin synthesis in the glycerol deprived cells. S. aureus possesses two cardiolipin synthase genes [36-38]. The accumulation of cardiolipin in stationary phase is attributed to Cls2, whereas cardiolipin synthesis in response to physiological stress depends on Cls1. The Cls1 stress response was rapid and does not require new protein synthesis [38]. Which of these Cls enzymes is responsible for the activation of cardiolipin synthesis in the absence of glycerol- $\mathrm{PO}_{4}$ remains to be determined. However, the conversion of PtdGro to cardiolipin appears to be a logical stress response to glycerol deficiency because the net effect is the release of intracellular glycerol that could be used to support PtdGro biosynthesis.

The data also suggest that the coupling of fatty acid synthesis and phospholipid has features that are similar to those observed in E. coli. The removal of the glycerol supplement results in diminished fatty acid synthesis that correlates with the accumulation of acyl-ACP. These accumulated acyl-ACPs are long-chain acyl-ACP end-products, and there is no evidence for the accumulation of acyl-ACP pathway intermediates. The fact that acyl-ACP does not rise to consume the entire ACP pool points to the regulation occurring at the initiation of fatty acid synthesis at the FabH step. This conclusion is consistent with the increased levels of malonyl-CoA, which indicate that the supply of malonyl groups is sufficient to complete the synthesis of an initiated acyl chain. However, malonyl-CoA levels only rose to $3.7 \%$ of the acetyl-CoA pool in the glycerol-deprived cells pointing to a biochemical regulatory mechanism that constrains the activity of acetyl-CoA carboxylase. FabH and acetyl-CoA carboxylase are key regulatory points in E. coli where acyl-ACP is thought to be the biochemical regulator of these two enzymes $[11,12]$. Our in vivo data are consistent with acyl-ACP targeting the same two proteins in S. aureus as in E. coli, but biochemical experiments will be required to verify this idea and define the mechanism of regulation.

\section{Conclusions}

PtdGro biosynthesis is not coupled to its utilization leading to the accumulation of pathway intermediates. The synthesis of cardiolipin significantly increased revealing a stress response to liberate glycerol- $\mathrm{PO}_{4}$ for PtdGro synthesis. Acyl-ACP accumulation correlated with a decrease in fatty acid synthesis. However, the regulation of fatty acid synthesis was not stringent enough to prevent the accumulation of intracellular fatty acids.

\section{Abbreviations}

glycerol-PO4: sn-glycerol-3-phosphate; PtdOH: Phosphatidic acid; Glc2 DAG: Glucosyl-diacylglycerol; PtdGro: Phosphatidylglycerol; DAG: Diacylglycerol; ACP: Acyl carrier protein; Lys-PtdGro: Lysylphosphatidylglycerol; acyl-PO 4 : Acyl-phosphate; LTA: Lipoteichoic acid.

\section{Competing interests}

The authors declare that they have no competing interests.

\section{Authors' contributions}

$J P, J Y$ and $C R$ designed the study, JP, JY, MF and PJ conducted the experiments. All authors analyzed the data, and CR prepared the first draft of the article. All authors read and approved the final manuscript.

\section{Acknowledgement}

This work was supported by National Institutes of Health Grant GM034496, Cancer Center Support Grant CA21765 and the American Lebanese Syrian Associated Charities.

Received: 24 September 2013 Accepted: 4 November 2013 Published: 16 November 2013

\section{References}

1. Zhang Y-M, Rock CO: Membrane lipid homeostasis in bacteria. Nat Rev Microbiol 2008, 6:222-233.

2. Cronan JE Jr, Rock CO: Chapter 3.6.4. Biosynthesis of membrane lipids. In Eco-Sal-Escherichia coli and Salmonella typhimurium: cellular and molecular biology. Edited by Böck I, Curtis R III, Kaper JB, Karp PD, Neidhardt FC, Nyström T, Slauch JM, Squires CL, Ussery D. Washington, DC: ASM Press; 2008. [Online] http://www.ecosal.org.

3. Yao J, Rock CO: Phosphatidic acid synthesis in bacteria. Biochim Biophys Acta 1831, 2013:495-502.

4. Parsons JB, Rock CO: Bacterial lipids: Metabolism and membrane homeostasis. Prog Lipid Res 2013, 52:249-276.

5. Heath RJ, Jackowski S, Rock CO: Guanosine tetraphosphate inhibition of fatty acid and phospholipid synthesis in Escherichia coli is relieved by overexpression of glycerol-3-phosphate acyltransferase $(p / s B)$. J Biol Chem 1994, 269:26584-26590.

6. Magnusson LU, Farewell A, Nystrom T: ppGpp: a global regulator in Escherichia coli. TIM 2005, 13:236-242.

7. Voelker TA, Davies HM: Alteration of the specificity and regulation of fatty acid synthesis of Escherichia coli by expression of a plant medium-chain acyl-acyl carrier protein thioesterase. J Bacteriol 1994, 176:7320-7327.

8. Jiang P, Cronan JE Jr: Inhibition of fatty acid synthesis in Escherichia coli in the absence of phospholipid synthesis and release of inhibition by thioesterase action. J Bacteriol 1994, 176:2814-2821.

9. Cho H, Cronan JE Jr: Defective export of a periplasmic enzyme disrupts regulation of bacterial fatty acid synthesis. J Biol Chem 1995, 270:4216-4219.

10. Heath RJ, Rock CO: Regulation of fatty acid elongation and initiation by acyl-acyl carrier protein in Escherichia coli. J Biol Chem 1996, 271:1833-1836. 
11. Heath RJ, Rock CO: Inhibition of b-ketoacyl-acyl carrier protein synthase III (FabH) by acyl-acyl carrier protein in Escherichia coli. J Biol Chem 1996, 271:10996-11000.

12. Davis MS, Cronan JE Jr: Inhibition of Escherichia coli acetyl coenzyme A carboxylase by acyl-acyl carrier protein. J Bacterio/ 2001, 183:1499-1503.

13. Lu Y-J, Zhang Y-M, Grimes KD, Qi J, Lee RE, Rock CO: Acyl-phosphates initiate membrane phospholipid synthesis in gram-positive pathogens. Molec Cell 2006, 23:765-772.

14. Parsons JB, Frank MW, Subramanian C, Saenkham P, Rock CO: Metabolic basis for the differential susceptibility of Gram-positive pathogens to fatty acid synthesis inhibitors. Proc Natl Acad Sci U S A 2011, 108:15378-15383.

15. Schujman GE, Paoletti L, Grossman AD, De Mendoza D: FapR, a bacterial transcription factor involved in global regulation of membrane lipid biosynthesis. Dev Cell 2003, 4:663-672.

16. Schujman GE, Guerin M, Buschiazzo A, Schaeffer F, Llarrull LI, Reh G, Vila AJ, Alzari PM, De Mendoza D: Structural basis of lipid biosynthesis regulation in Gram-positive bacteria. EMBO J 2006, 25:4074-4083.

17. Albanesi D, Reh G, Guerin ME, Schaeffer F, Debarbouille M, Buschiazzo A, Schujman GE, De Mendoza D, Alzari PM: Structural basis for feed-rorward transcriptional regulation of membrane lipid homeostasis in Staphylococcus aureus. PLoS Pathog 2013, 9:e1003108.

18. Cronan JE Jr, Vagelos PR: Metabolism and function of the membrane phospholipids of Escherichia coli. Biochim Biophys Acta 1972, 265:25-60.

19. Mindich L: Induction of Staphylococcus aureus lactose permease in the absence of glycerolipid synthesis. Proc Natl Acad Sci U S A 1971, 68:420-424

20. Ray PH, White DC: Effect of glycerol deprivation on the phospholipid metabolism of a glycerol auxotroph of Staphylococcus aureus. J Bacteriol 1972, 109:668-677.

21. Mindich L: Membrane synthesis in Bacillus subtilis. II. Integration of membrane proteins in the absence of lipid synthesis. J Mol Biol 1970, 49:433-439.

22. Mindich L: Membrane synthesis in Bacillus subtilis. I. Isolation and properties of strains bearing mutations in glycerol metabolism. $J \mathrm{Mol} B \mathrm{BiO}$ 1970, 49:415-432.

23. Paoletti L, Lu Y-J, Schujman GE, De Mendoza D, Rock CO: Coupling of fatty acid and phospholipid synthesis in Bacillus subtilis. J Bacteriol 2007, 189:5816-5824.

24. Kreiswirth BN, Lofdahl S, Betley MJ, O'Reilly M, Schlievert PM, Bergdoll MS, Novick RP: The toxic shock syndrome exotoxin structural gene is not detectably transmitted by a prophage. Nature (London) 1983, 305:709-712.

25. Parsons JB, Yao J, Frank MW, Jackson P, Rock CO: Membrane disruption by antimicrobial fatty acids releases low molecular weight proteins from Staphylococcus aureus. J Bacteriol 2012, 194:5294-5304.

26. Zhong J, Karberg M, Lambowitz AM: Targeted and random bacterial gene disruption using a group II intron (targetron) vector containing a retrotransposition-activated selectable marker. Nucleic Acids Res 2003, 31:1656-1664.

27. Bligh EG, Dyer WJ: A rapid method of total lipid extraction and purification. Can J Biochem Physiol 1959, 37:911-917.

28. Minkler PE, Kerner J, Ingalls ST, Hoppel CL: Novel isolation procedure for short-, medium-, and long-chain acyl-coenzyme A esters from tissue. Anal Biochem 2008, 376:275-276.

29. Haynes CA, Allegood JC, Sims K, Wang EW, Sullards MC, Merrill AH Jr: Quantitation of fatty acyl-coenzyme As in mammalian cells by liquid chromatography-electrospray ionization tandem mass spectrometry. J Lipid Res 2008, 49:1113-1125.

30. Bell RM: Mutants of Escherichia coli defective in membrane phospholipid synthesis: macromolecular synthesis in an sn-glycerol 3-phosphate acyltransferase $K_{m}$ mutant. J Bacteriol 1974, 117:1065-1076.

31. Vallari DS, Jackowski S, Rock CO: Regulation of pantothenate kinase by coenzyme A and its thioesters. J Biol Chem 1987, 262:2468-2471.

32. Grundling A, Schneewind O: Synthesis of glycerol phosphate lipoteichoic acid in Staphylococcus aureus. Proc Natl Acad Sci U S A 2007, 104:8478-8483.
33. Jerga A, Lu Y-J, Schujman GE, De Mendoza D, Rock CO: Identification of a soluble diacylglycerol kinase required for lipoteichoic acid production in Bacillus subtilis. J Biol Chem 2007, 282:21738-21745.

34. Kiriukhin MY, Debabov DV, Shinabarger DL, Neuhaus FC: Biosynthesis of the glycolipid anchor in lipoteichoic acid of Staphylococcus aureus RN4220: role of YpfP, the diglucosyldiacylglycerol synthase. J Bacteriol 2001, 183:3506-3514.

35. Oku Y, Kurokawa K, Ichihashi N, Sekimizu K: Characterization of the Staphylococcus aureus mprF gene, involved in lysinylation of phosphatidylglycerol. Microbiology 2004, 150:45-51.

36. Koprivnjak T, Zhang D, Ernst CM, Peschel A, Nauseef WM, Weiss JP: Characterization of Staphylococcus aureus cardiolipin synthases 1 and 2 and their contribution to accumulation of cardiolipin in stationary phase and within phagocytes. J Bacterio/ 2011, 193:4134-4142.

37. Tsai M, Ohniwa RL, Kato Y, Takeshita SL, Ohta T, Saito S, Hayashi H, Morikawa K: Staphylococcus aureus requires cardiolipin for survival under conditions of high salinity. BMC Microbiol 2011, 11:13.

38. Ohniwa RL, Kitabayashi K, Morikawa K: Alternative cardiolipin synthase Cls1 compensates for stalled Cls2 function in Staphylococcus aureus under conditions of acute acid stress. FEMS Microbiol Lett 2013, 338:141-146.

doi:10.1186/1471-2180-13-260

Cite this article as: Parsons et al:: Phosphatidylglycerol homeostasis in glycerol-phosphate auxotrophs of Staphylococcus aureus. BMC Microbiology 2013 13:260.

\section{Submit your next manuscript to BioMed Central and take full advantage of:}

- Convenient online submission

- Thorough peer review

- No space constraints or color figure charges

- Immediate publication on acceptance

- Inclusion in PubMed, CAS, Scopus and Google Scholar

- Research which is freely available for redistribution

Submit your manuscript at www.biomedcentral.com/submit
C) Biomed Central 